\title{
The first aid management of epistaxis by accident and emergency department staff
}

\author{
G. W. MCGARRY \& C. MOULTON
}

Department of Otolaryngology and Head and Neck Surgery and Department of Accident and Emergency Medicine, Glasgow Royal Infirmary, Glasgow G4 OSF

\section{SUMMARY}

Most nose bleeds can be controlled by compressing the ala nasi, thus applying direct pressure over Little's area. The ability to demonstrate the correct position for this manoeuvre was assessed in $\mathbf{1 1 5}$ members of the staff of the accident and emergency (A\&E) department of a major teaching hospital. Overall, the correck response rate was only $33 \%$ and even trained medical and nursing staff achieve $\$$ less than a $50 \%$ success rate. Increased awareness of this simple and effective tech nique is recommended.

\section{INTRODUCTION}

Epistaxis is the most common ear, nose and throat (ENT) problem presenting to an A\&E department. The vast majority of nose bleeds $(90 \%)$ arise from Little's area on the anterior part of the nasal septum (Rains \& Ritchie, 1984). Since the time of Hippocrates it has been recognized that simple digital pressure over the ala nasi will achieve haemostasis in most cases (Shaheen, 1987). Hence compression of this area is advocated as a primary treatment for epistaxis in both standard first aid manuals (St John Ambulance et al., 1987) and commonly-used A\&E texts (Yates \& Redmond, 1985). In order to assess the ability of A\&E staff to apply the haemostatic pressure in the correct position the following survey was performed.

\section{METHODS}

A total of 115 A\&E staff, including doctors (25), nurses (60), paramedics (15) and non-clinical staff (15), were asked to demonstrate the method by which they would

Correspondence: Dr C. Moulton, Senior Registrar in AEE Medicine, Department of AEE Medicine, North Manchester General Hospital, Delaunays Road, Crumpsall, Manchester M8 6RB, U.K. 
Table 1. Position demonstrated for first aid control of epistaxis by A\&E staff

\begin{tabular}{lrcr}
\hline Designation & No & Correct & Incorrect \\
\hline Sister & 10 & 6 & 4 \\
RGN & 30 & 9 & 21 \\
SEN & 10 & 2 & 8 \\
Student nurse & 10 & 1 & 9 \\
Senior doctor & 10 & 8 & 2 \\
SHO & 15 & 7 & 8 \\
Paramedic & 15 & 3 & 12 \\
Non-clinical & 15 & 2 & 13 \\
All clinical staff & 100 & 36 & 64 \\
All A\&E staff & 115 & 38 & 77 \\
\hline
\end{tabular}

attempt to control a simple nose bleed using digital pressure. A correct response was recorded when the ala nasi were compressed. An incorrect response was recorded when pressure was applied elsewhere. The exact position used was noted in each case.

\section{RESULTS}

The overall correct response rate was 33\%; for trained medical and nursing staff it was $43 \%$. The breakdown of these figures is shown in Table 1. Clinical assistants, registrars, senior registrars and consultants are grouped together as 'senior doctors' for the purposes of this study. The commonest incorrect site demonstrated was over the lower part of the nasal bones.

\section{Discussion:}

Despite the high incidence of epistaxis, A\&E staff show a surprisingly low level of ability to demonstrate correctly the standard first aid manoeuvre for this situation. It appears that large numbers of patients are being managed inappropriately with compression of the wrong part of the nose. Although only one teaching hospital $\mathrm{A} \& \mathrm{E}$ department was surveyed there is no reason to believe that similar findings would not be obtained elsewhere. Ignorance of the correct technique will result in increased blood loss and unnecessary referral to specialist ENT services. The appropriate knowledge is however available, as evinced by the relatively high correct response rate obtained from both the sisters and the senior doctors of the A\&E department. The high number of staff who attempted to compress the nasal bones suggests that textbooks and teachers need to be more specific and clear about the exact site to be used. Increased training of A\&E staff in the correct application of this technique is recommended as a cost effective method of treating the majority of patients with epistaxis. 


\section{REFERENCES}

Rains A. J. H. \& Ritchie H. D. (1984) (Eds) Bailey and Love's Short Practice of Surgery, 19th Edition, pp. 567. Lewis, London.

Shaheen O. H. (1987) Epistaxis. In: Mackay I. S. \& Bull T. R. (Eds) Scott-Broum's Otolaryngology, 5th Edition Volume 4, pp. 272-282. Butterworths, London.

St John Ambulance, St Andrew's Ambulance Association, The British Red Cross Society (1987) First Aid Manual, 5th Edition, pp 71. Dorling Kindersley, London.

Yates D. W. \& Redmond A. D. (1985) Lecture Notes on Accident and Emergency Medicine, pp. 363. Blackwell Scientific Publications, Oxford. 